\title{
Indium-tin oxide thin films by metal-organic decomposition
}

\author{
Dennis Gallagher, ${ }^{a}$ Francis Scanlan, ${ }^{\text {b) }}$ Raymond Houriet, Hans Jörg Mathieu, \\ and Terry A. Ring ${ }^{\text {), d) }}$ \\ Laboratoire de Technologie des Poudres, École Polytechnique Fédérale de Lausanne, \\ CH-1015 Lausanne, Switzerland
}

(Received 22 June 1992; accepted 26 July 1993)

$\mathrm{In}_{2} \mathrm{O}_{3}-\mathrm{SnO}_{2}$ films were produced by thermal decomposition of a deposit which was dip coated on borosilicate glass substrates from an acetylacetone solution of indium and tin acetoacetonate. Thermal analysis showed complete pyrolysis of the organics by $400{ }^{\circ} \mathrm{C}$. The thermal decomposition reaction generated acetylacetone gas and was found to be first order with an activation energy of $13.6 \mathrm{Kcal} / \mathrm{mole}$. Differences in thermal decomposition between the film and bulk materials were noted. As measured by differential scanning calorimetry using a $40{ }^{\circ} \mathrm{C} / \mathrm{min}$ temperature ramp, the glass transition temperature of the deposited oxide film was found to be $\sim 462{ }^{\circ} \mathrm{C}$, and the film crystallization temperature was found to be $\sim 518{ }^{\circ} \mathrm{C}$. For film fabrication, thermal decomposition of the films was performed at $500{ }^{\circ} \mathrm{C}$ in air for $1 \mathrm{~h}$ followed by reduction for various times at $500{ }^{\circ} \mathrm{C}$ in a reducing atmosphere. Crystalline films resulted for these conditions. A resistivity of $\sim 1.01 \times 10^{-3} \Omega \cdot \mathrm{cm}$, at $8 \mathrm{wt}$. \% tin oxide with a transparency of $\sim 95 \%$ at $400 \mathrm{~nm}$, has been achieved for a $273 \mathrm{~nm}$ thick film.

\section{INTRODUCTION}

Ceramic films are important for optical and protective coatings, and are becoming increasingly important in the production of electronic devices. For many of these coating applications, films can be deposited from metal-organic solutions. Indium-tin oxide (ITO) films are useful for electrical contacts as well as antireflective coatings because they combine high transparency $(>87 \%)$ with low resistivity $\left(<29 \mathrm{ohm} / \mathrm{cm}^{2}\right) \cdot{ }^{1-3}$ Several effective methods are used to prepare these coatings, which include sputtering, evaporation, and metal-organic processes. ${ }^{1}$ The economical metal-organic process is particularly attractive because of its applicability to diverse shapes and large objects. Arfsten et al. ${ }^{3,4}$ first showed that ITO films prepared by a sol-gel process could have good electrical and optical properties. Later, Maruyama and Kojima ${ }^{1}$ produced low resistivity films made from acetylacetonate solutions and described some of the thermal treatment and compositional effects on the conductivity of such ITO films. For the metalorganic processing of ITO to become a more attractive processing route, a basic understanding of the chemistry and processing characteristics is needed.

\footnotetext{
a)Present address: Phillips Laboratories, 345 Scarborough Road, Briarcliff Manor, New York 10510.

b) Present address: Anjou Recherche-CGE, B.P. 76, F-78600 MaisonsLafitte.

c) Present address: Department of Chemical and Fuels Engineering,

University of Utah, Salt Lake City, Utah 84112.

d) Author to whom correspondence should be sent.
}

The processing of ITO by any deposition route is complex because of the difficulty to control the tindoping level, the oxide reduction, the microstructure, and the crystallinity. For evaporated and sputter-coated ITO films, these relationships have been well studied. The tin dopant improves the film conductivity when $\mathrm{Sn}^{4+}$ replaces $\mathrm{In}^{3+}$ in the $\mathrm{In}_{2} \mathrm{O}_{3}$ cation sublattice, behaving as an $n$-type donor. ${ }^{5}$ This is true for tin levels up to $6 \pm 2$ at. $\%,{ }^{6}$ its substitutional limits in the crystal structure. At higher tin concentrations, ionizable $\mathrm{Sn}_{2}^{\circ} \mathrm{O}_{i}^{\prime \prime}$ and nonionizable $\mathrm{Sn}_{2} \mathrm{O}_{4}$ structural defects ${ }^{1}$ as well as tin oxide $\left(\mathrm{SnO}, \mathrm{SnO}_{2}, \mathrm{Sn}_{3} \mathrm{O}_{4}\right)$ phases ${ }^{7}$ form, thus decreasing conductivity. Experimentally, improvements in conductivity have been seen for tin levels up to 9 at. \% in sputtered films, 11 at. $\%$ in evaporated films, and 16 at. \% in pyrolytic and sol-gel films. Conductivity can also be increased by the reduction of $\operatorname{In}_{2} \mathrm{O}_{3}$, thus creating doubly charged oxygen vacancies.

To better understand metal-organic processing, films were dip coated on a substrate using an acetylacetone solution of $\operatorname{In}\left(\mathrm{NO}_{3}\right)_{3}$ and $\mathrm{SnCl}_{4}$. These films were then thermally decomposed to the oxide which were further reduced yielding higher electrical conductivity while maintaining their transparency.

\section{EXPERIMENTAL PROCEDURE}

Alkali free borosilicate glass substrates ${ }^{8}$ were used to avoid sodium diffusion into the ITO layer during the thermal treatments, as is seen with ordinary soda glass substrates. An x-ray fluorescence ${ }^{9}$ spectrum of the borosilicate substrate, obtained by illumination with a 
rhodium $\mathrm{x}$-ray tube operated at $40 \mathrm{keV}$, showed that it contains:

\begin{tabular}{lr} 
Element & \multicolumn{1}{c}{ Counts/s } \\
\hline $\mathrm{Ba}(\mathrm{LA})$ & $252.2 \pm 1.3$ \\
$\mathrm{Sr}(\mathrm{KA})$ & $96.8 \pm 1.0$ \\
$\mathrm{Si}(\mathrm{KA})$ & $94.9 \pm 1.2$ \\
$\mathrm{Zr}(\mathrm{KA})$ & $47.1 \pm 0.9$ \\
$\mathrm{Ti}(\mathrm{KA})$ & $43.4 \pm 2.0$ \\
$\mathrm{Al}(\mathrm{KA})$ & $13.2 \pm 0.5$ \\
$\mathrm{Y}(\mathrm{KA})$ & $1.4 \pm 0.3$ \\
$\mathrm{Ca}(\mathrm{KA})$ & $1.2 \pm 0.2$ \\
$\mathrm{As}(\mathrm{LA})$ & $0.8 \pm 0.4$
\end{tabular}

A measure of the surface roughness of the substrate was measured by atomic force microscopy, ${ }^{10}$ which showed a root mean square (RMS) roughness of $6.7 \AA$. To provide good substrate wetting by the acetylacetone solutions, the substrates were cleaned with laboratory detergent, rinsed with de-ionized water, soaked in concentrated nitric acid for $1 \mathrm{~h}$, rinsed again with de-ionized water, dried in a vacuum oven at $60{ }^{\circ} \mathrm{C}$, rinsed with methanol, and dried again before being used for dip coating.

\section{A. Dip coating solution preparation}

Separate $0.5 \mathrm{M}$ stock solutions of indium and tin acetylacetonate were prepared from indium nitrate $\left[\mathrm{In}\left(\mathrm{NO}_{3}\right)_{3}\right] \cdot 2 \mathrm{H}_{2} \mathrm{O}^{11}$ and tin chloride $\left(\mathrm{SnCl}_{4}\right)^{12}$ by dissolving each separately in an acetylacetone $\left(\mathrm{C}_{5} \mathrm{H}_{8} \mathrm{O}_{2}\right)^{12}$ solvent. These solutions were refluxed for $24 \mathrm{~h}$ at $150{ }^{\circ} \mathrm{C}$ (boiling point of acetylacetone, $143{ }^{\circ} \mathrm{C}$ ) followed by a distillation at $120^{\circ} \mathrm{C}$ to remove water, nitric acid, and hydrochloric acid which had been introduced by the hydrated indium nitrate and tin chloride. Complexation reactions took place in each solution, which were characterized by Fourier Transform Infrared ${ }^{13}$ and uvvisible spectroscopy. The solution used for dip coating was diluted to $0.25 \mathrm{M}$ indium to reduce its viscosity. Various amounts of tin dopant were added to study the effect on the resulting oxide film. These levels of tin affected the solution viscosity slightly. The infrared spectra $^{13}$ of the $0.5 \mathrm{M}$ acetylacetonate solutions were recorded using a $0.05 \mathrm{~mm}$ path length liquid cell.

\section{B. Film formation}

The substrates were dipped in the $0.5 \mathrm{M}$ acetylacetonate solution by a simple mechanical pulley system where the weight of the substrate was offset by a sealed cylinder that floated on a column of water; as water flowed out of the cylinder at a constant rate, the substrate was pulled from the solution at a constant velocity. All samples were prepared by a single dip in the acetylacetone solution and were withdrawn at different constant velocities. The resultant films were then dried in a vacuum drying oven at $100{ }^{\circ} \mathrm{C}$ overnight. Film thickness measurements were made using a Tencor Alpha-Step 200 profilometer. The film thicknesses measured for these samples ranged between 250 and $500 \mathrm{~nm}$ after thermal decomposition, depending on the dipping velocity and the solution viscosity.

For accurate thermal gravimetric analysis (TGA), an increase in the film weight was necessary. This was accomplished by using silica spheres as the substrate in contrast to the flat borosilicate glass substrate. The cleaning procedure for these spheres was the same as that for the borosilicate substrates. After pretreatment, the spheres were coated by flowing the $0.5 \mathrm{M}$ acetylacetonate solution over them and through a $1 \mu \mathrm{m}$ vacuum filter and then dried in a vacuum drying oven at $100{ }^{\circ} \mathrm{C}$ overnight.

For generation of bulk material, $20 \mathrm{ml}$ of $0.5 \mathrm{M}$ acetylacetonate solution was dried in a vacuum drying oven at $100{ }^{\circ} \mathrm{C}$ overnight. This material was used in TGA to compare the thermal decompositions of film and bulk material.

\section{Heat treatment}

During heat treatment, a $200 \mathrm{ml} / \mathrm{min}$ gas flow was maintained through a $10 \mathrm{~cm}$ outside diameter quartz tube mounted within a box furnace. The various gases used for the thermal treatments included dry air, argon, forming gas $\left(92 \% \mathrm{~N}_{2}, 8 \% \mathrm{H}_{2}\right)$, and nitrogen. All were obtained from Carbagas. ${ }^{14}$ The samples were initially heated in dry air to decompose thermally the metalorganic film. The resulting oxide was then reduced by heat-treating in forming gas. These reduced samples were cooled to room temperature in reducing gas to avoid oxidation of the surface layer. The effects of heat treatment alone were studied using either nitrogen or argon atmospheres.

The weight loss of the film-coated silica spheres and bulk material during thermal decomposition was evaluated by $\mathrm{TGA}^{15}$ from room temperature to $550{ }^{\circ} \mathrm{C}$ with a heating rate of $40{ }^{\circ} \mathrm{C} / \mathrm{min}$ in a $200 \mathrm{ml} / \mathrm{min}$ dry air flow. Differential scanning calorimetry ${ }^{16}$ (DSC) measurements were also performed for the film coated on glass spheres and bulk material at a heating rate of $40{ }^{\circ} \mathrm{C} / \mathrm{min}$ with a $50 \mathrm{ml} / \mathrm{min}$ dry air flow.

The gases given off during thermal decomposition were analyzed at various pyrolysis temperatures using a temperature programmed pyrolysis ${ }^{17} /$ gas chromato-

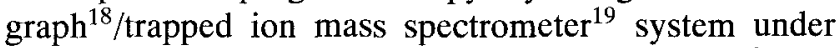
conditions similar to those described previously. ${ }^{20}$ The film-coated glass spheres were heated at $200{ }^{\circ} \mathrm{C} / \mathrm{s}$ up to the desired pyrolysis temperature in a helium ${ }^{14}$ carrier gas flow where the temperature was held for $10 \mathrm{~min}$. A $10 \mathrm{~s}$ pulse of dry air was added during heatup to give an oxidizing atmosphere. The gases from pyrolysis 
were conveyed in a heated line to the gas chromatograph equipped with a $30 \mathrm{~m}$ long, $0.032 \mathrm{~mm}$ (i.d.) capillary column with methylsilicone phase, maintained at $100{ }^{\circ} \mathrm{C}$, which separated the various gases such that their time of arrival at the mass spectrometer was different. The transfer line to the mass spectrometer was also heated to prevent condensation. Once inside the mass spectrometer, the gas molecules were ionized and their masses determined. A mass range of 1 to 3300, as well as the total accumulated mass, was measured as a function of time. The time dependence of the total mass accumulated can be interpreted as a signal similar to that of a gas chromatograph detector.

The surface chemistry and structure of the film were analyzed by electron spectroscopy for chemical analysis (ESCA) ${ }^{21}$ secondary ion mass spectrometry (SIMS), ${ }^{22}$ and atomic force microscopy ${ }^{10}$ (AFM). SIMS experiments were performed with $\mathrm{Ar}^{+}$ions as the sputtering gas at an acceleration voltage of $5 \mathrm{kV}$ and a current of $50 \mathrm{nA}$.

\section{Optical and electrical properties of the films}

The film conductivity was measured by the van der Pauw method ${ }^{23}$ and the four point probe technique. ${ }^{24}$ Optical transparency of the film was measured by uv-visible spectroscopy ${ }^{25}$ over a wavelength range of $300 \mathrm{~nm}$ to $900 \mathrm{~nm}$.

\section{RESULTS AND DISCUSSION}

\section{A. Dip-coating solution chemistry}

The solvent acetylacetone ( 2,4 pentanedione) exists as two tautermers: the ketone $\mathrm{CH}_{3} \mathrm{COCH}_{2} \mathrm{COCH}_{3}$ and the enol $\mathrm{CH}_{3} \mathrm{C}(\mathrm{OH}) \mathrm{CHCOCH}_{3}$ forms. ${ }^{26}$ The enol form, corresponding to $85 \%$ at room temperature, is stabilized by hydrogen bonding between the alcohol $(\mathrm{OH})$ group and the ketone group. Separate $0.5 \mathrm{M}$ stock acetylacetonate solutions were prepared. Solutions of $\mathrm{SnCl}_{4}$ immediately changed color and gave off a gaseous $\mathrm{HCl}$, indicating a chemical reaction. Solutions of $\operatorname{In}\left(\mathrm{NO}_{3}\right)_{3}$ underwent a slower photodecomposition, as shown in the uv-vis spectra of Fig. 1. After $17 \mathrm{~h}$ at $25{ }^{\circ} \mathrm{C}, \operatorname{In}\left(\mathrm{NO}_{3}\right)_{3}$ in acetylacetone has an absorption maxima at $346 \mathrm{~nm} \cdot{ }^{27}$ This datum was analyzed for its reaction kinetics and was found to be pseudo-first order with a rate constant of $1.81 \times 10^{-4} \mathrm{~min}^{-1}$ at $25^{\circ} \mathrm{C}$ and $6.67 \times 10^{-4} \mathrm{~min}^{-1}$ at $150{ }^{\circ} \mathrm{C}$, which gives an activation energy of $7.2 \mathrm{kcal} / \mathrm{mole}$. The color change was accelerated slightly by exposure to light.

In order to characterize the chemistry of these starting solutions, both Fourier Transform Infrared Spectroscopy (FTIR) and Mass Spectroscopy measurements were performed on the separate precursor solutions. The FTIR spectrum for the reacted indium solution is shown in Fig. 2 and bears a close resemblance to

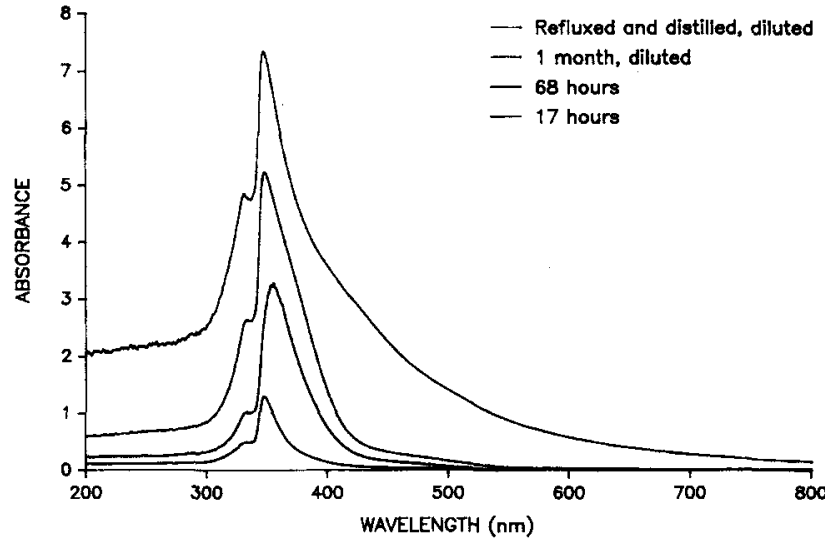

FIG. 1. The uv-visible spectrum of indium nitrate mixed with acetylacetone.

that of the $\mathrm{Fe}\left(\mathrm{C}_{5} \mathrm{H}_{7} \mathrm{O}_{2}\right)_{3}$ spectrum. As a result similar peak assignments seem appropriate, suggesting that indium acetylacetonate $\left[\operatorname{In}\left(\mathrm{C}_{5} \mathrm{H}_{7} \mathrm{O}_{2}\right)_{3}\right]$ is the product of the reaction between $\left[\operatorname{In}\left(\mathrm{NO}_{3}\right)_{3}\right] \cdot 2 \mathrm{H}_{2} \mathrm{O}$ and acetylacetone. The FTIR spectrum for the reacted tin solution is shown in Fig. 3 and suggests that tin acetylacetonate $\left[\mathrm{Sn}\left(\mathrm{C}_{5} \mathrm{H}_{7} \mathrm{O}_{2}\right)_{4}\right]$ is the product of the reaction between $\mathrm{SnCl}_{4}$ and acetylacetone. The peak assignments for both indium ${ }^{28}$ and $\operatorname{tin}^{29-31}$ solutions are given in Table $\mathrm{I}$. Thermal desorption mass spectroscopy measurements of the indium acetylacetonate with its characteristic peaks at masses 412, 313, 214, and 115 (not shown) compare favorably to those measured by Inagaki and Ohkubo. ${ }^{32}$ As a result, the following reactions result for the dissolution of $\operatorname{In}\left(\mathrm{NO}_{3}\right)_{3} \cdot 2 \mathrm{H}_{2} \mathrm{O}$ and $\mathrm{SnCl}_{4}$ in acetylacetone.

$$
\begin{aligned}
& \operatorname{In}\left(\mathrm{NO}_{3}\right)_{3} \cdot 2 \mathrm{H}_{2} \mathrm{O}+ 3 \mathrm{C}_{5} \mathrm{H}_{8} \mathrm{O}_{2} \longrightarrow \\
& \mathrm{In}\left(\mathrm{C}_{5} \mathrm{H}_{7} \mathrm{O}_{2}\right)_{3}+3 \mathrm{HNO}_{3}+2 \mathrm{H}_{2} \mathrm{O} \\
& \mathrm{SnCl}_{4}+2 \mathrm{C}_{5} \mathrm{H}_{8} \mathrm{O}_{2} \rightarrow \operatorname{Sn}\left(\mathrm{C}_{5} \mathrm{H}_{7} \mathrm{O}_{2}\right)_{4}+4 \mathrm{HCl}
\end{aligned}
$$

After distillation, these starting solutions are chelates of acetylacetone with the indium probably in a bipyramid bonding configuration with each acetylacetonate

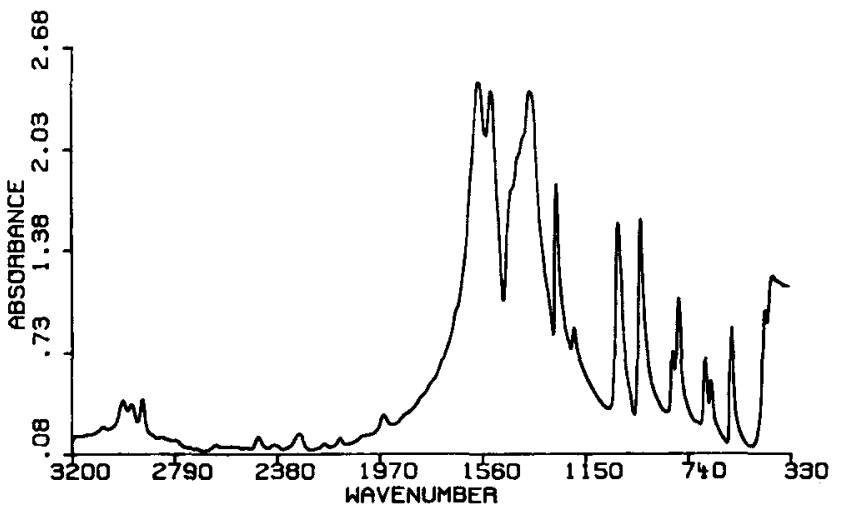

FIG. 2. FTIR spectrum of indium acetylacetonate solution. 


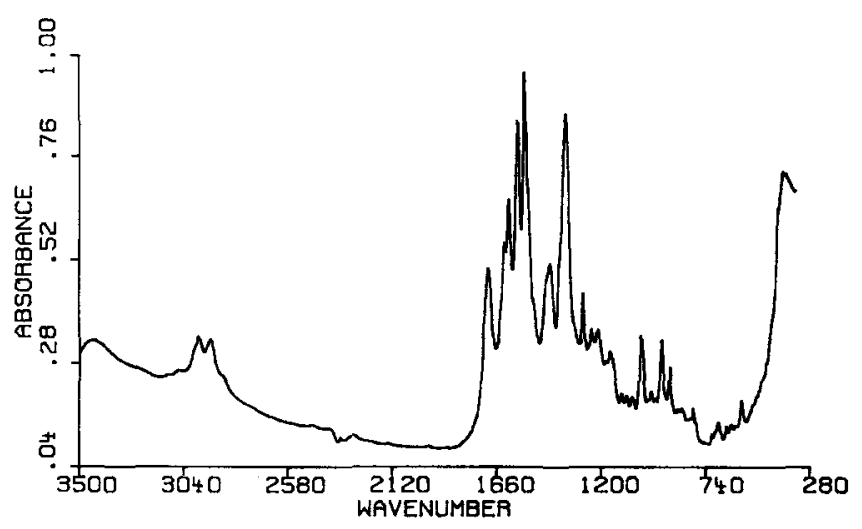

FIG. 3. FTIR spectrum of tin acetylacetonate solution.

complexing two of the six bonding sites and the tin in a $s p^{3}$ tetrahedral bonding configuration with the four bonding sites occupied by the acetylacetonate, as presented in Fig. 4. These structures have not been independently confirmed.

The distillation step served to remove water, nitric acid, and hydrochloric acid from the stock solutions

TABLE I. Frequencies and band assignments for indium and tin acetylacetonate complexes.

\begin{tabular}{|c|c|c|}
\hline \multicolumn{2}{|c|}{ Vibrational frequencies $(\mathrm{cm})^{-1}$} & \multirow[b]{2}{*}{ Band assignments } \\
\hline Indium & Tin & \\
\hline 3078 & 3065 & $v(\mathrm{CH})$ \\
\hline 2997 & Buried & $v_{a s}$ methyl \\
\hline 2961 & 2974 & $v_{a s}$ methylene $\} v\left(\mathrm{CH}_{3}\right)$ \\
\hline 2919 & 2924 & $v_{s}$ methyl $\int$ \\
\hline $\left.\begin{array}{l}1580 \\
1573\end{array}\right\}$ & 1567 & $v(\mathrm{C}-\mathrm{C})+v(\mathrm{C}-\mathrm{O})$ \\
\hline 1556 & $\cdots$ & Combination \\
\hline 1527 & 1531 & $v(\mathrm{C} \because \mathrm{O})+v(\mathrm{C} \ddot{ } \mathrm{C})$ \\
\hline 1442 & $\cdots$ & $\delta(\mathrm{CH})+v(\mathrm{C} \cdots \mathrm{C})$ \\
\hline $\left.\begin{array}{l}1421 \\
1402\end{array}\right\}$ & 1426 & $\delta_{d}\left(\mathrm{CH}_{3}\right)$ \\
\hline 1370 & 1352 & $\delta_{s}\left(\mathrm{CH}_{3}\right)$ coupled with $\mathrm{CO} v$ \\
\hline 1266 & 1279 & $v\left(\mathrm{C}-\mathrm{CH}_{3}\right)+v(\mathrm{C} \cdots \mathrm{C})$ \\
\hline 1197 & 1214 & $\delta(\mathrm{CH})+v\left(\mathrm{C}-\mathrm{CH}_{3}\right)$ \\
\hline 1022 & 1024 & $\rho_{r}\left(\mathrm{CH}_{3}\right)$ \\
\hline 930 & 937 & $v(\mathrm{C} \cdot \mathrm{C})+v(\mathrm{C} \cdots \mathrm{O})$ \\
\hline $\left.\begin{array}{l}803 \\
779\end{array}\right\}$ & 797 & $\pi(\mathrm{CH})$ \\
\hline 672 & 680 & $v\left(\mathrm{C}-\mathrm{CH}_{3}\right)+$ ring def. $+v(\mathrm{MO})$ \\
\hline 649 & 647 & $\pi \mathrm{CH}_{3}-\mathrm{C}_{\backslash}^{\prime}$ \\
\hline 569 & 582 & Ring def. $+v(\mathrm{MO})$ \\
\hline 434 & $\cdots$ & $v(\mathrm{MO})+v\left(\mathrm{C}-\mathrm{CH}_{3}\right)$ \\
\hline $\left.\begin{array}{l}412 \\
404\end{array}\right\}$ & $\left.\begin{array}{l}416 \\
398\end{array}\right\}$ & Ring deformations \\
\hline
\end{tabular}

$\overline{(v) \text { stretching, }(\delta) \text { in-plane bending, }\left(\rho_{r}\right) \text { rocking, and }(\pi) \text { out-of- }}$ plane bending.

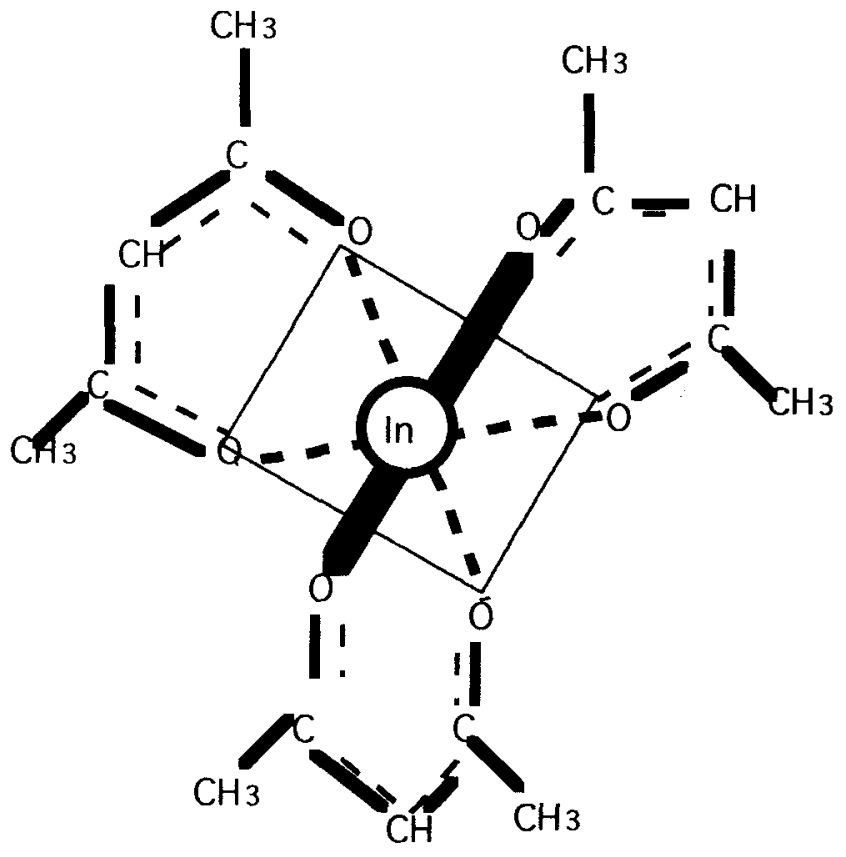

(a)

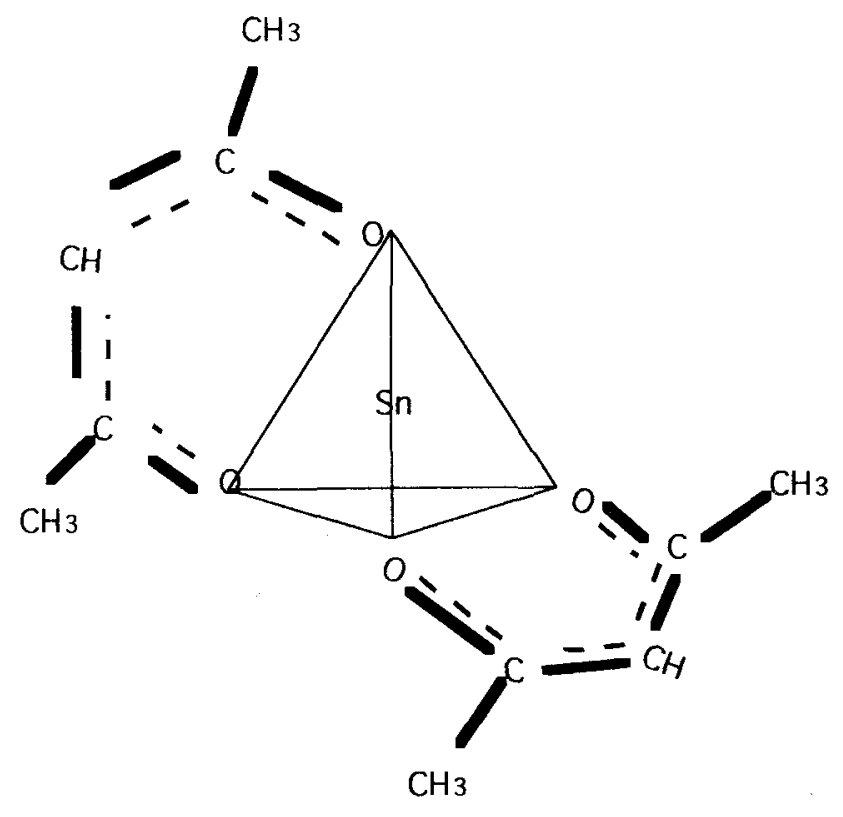

(b)

FIG. 4. Probable bonding of acetylacetonate complexes of (a) indium and (b) tin in acetylacetone solution.

which had been introduced by the metal salt raw materials. If distillation was not performed, white precipitates were formed that thermally decompose starting at 450 and ending at $550{ }^{\circ} \mathrm{C}$. Identification of the chemical nature of the precipitates has been inconclusive. However, the tin stock solution is responsible for their appearance; the indium solution alone without distillation did not show precipitate formation. Only in mixture with the 
tin solution were precipitates observed. With distillation, a mixed solution that causes these white precipitates can be restored to a solution which does not form these precipitates. The final solution used for dip coating was diluted to $0.25 \mathrm{M}$ indium to reduce the viscosity. Various amounts of tin dopant were added, which consequently affected the solution viscosity slightly.

\section{B. Dip coating}

Samples were prepared by a single dip in the indiumtin acetylacetonate solution and were withdrawn at a constant velocity. The deposited thicknesses ranged between 250 and $380 \mathrm{~nm}$ after thermal decomposition, depending on the solution viscosity altered by the tin dopant concentration. The thickness, $\delta$, of the oxide layer after thermal decomposition can be correlated (after consideration of the resulting oxide content in the metalorganic solution after thermal decomposition, $C$ ) with an equation developed by Deryagin ${ }^{33}$ for dip coating of Newtonian solutions given by:

$$
\delta=C \frac{2}{3} \sqrt{\frac{V \eta}{\rho g \sin \theta}}
$$

where $V$ is the constant dipping speed, $g$ is the gravitational constant, $\theta$ is the angle that the substrate is pulled from the solution ( $90^{\circ}$ in this case), $\eta$ is the solution viscosity, and $\rho$ is the solution density. This relationship relates the film thickness to the dipping velocity.

\section{Thermal decomposition}

The decomposition of the ITO film was evaluated by TGA using $200 \mu \mathrm{m}$ amorphous silica spheres as the substrate. These results are contrasted with those of a bulk powder produced by evaporation of the same starting solution. Figure 5 presents these TGA results. The bulk ITO powders showed discrete decomposition steps at $120,180,320$, and $440{ }^{\circ} \mathrm{C}$, although reactions were not completed until almost $500{ }^{\circ} \mathrm{C}$. The steps at

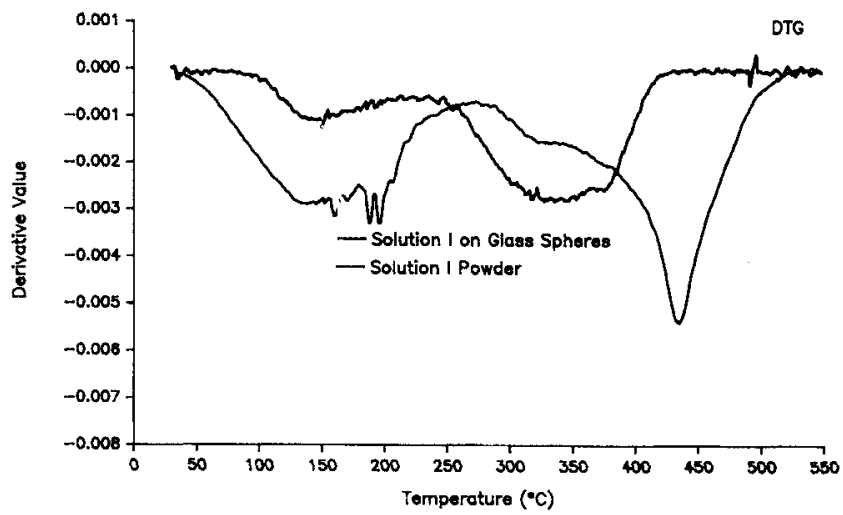

FIG. 5. DTG of $8 \%$ tin oxide ITO film and powder derived from dried solution.
180,320 , and $440{ }^{\circ} \mathrm{C}$ are likely to be the removal of one acetylacetonate group per metal, polymerization where the metal atoms is joined by shared acetylacetonate ligand, and then a stepwise removal and further polymerization, followed by oxidative removal of bridging acetylacetonate groups, as was observed with thermal decomposition of iron acetylacetonate in oxygen. ${ }^{34}$ The ITO film-coated silica spheres decomposed quite differently, producing only two decomposition steps: at $145^{\circ} \mathrm{C}$, near the boiling point of acetylacetone, $143{ }^{\circ} \mathrm{C}$, and a broad step at $335^{\circ} \mathrm{C}$. All weight loss reactions were completed by $400{ }^{\circ} \mathrm{C}$, nearly $100{ }^{\circ} \mathrm{C}$ less than that for the bulk material. This completion temperature corresponds to one where visual inspection of samples prepared on the flat glass substrates showed transparency. A DSC of the film thermal decomposition is shown in Fig. 6. The broad step at $335^{\circ} \mathrm{C}$ is exothermic. The thermal decomposition at $335{ }^{\circ} \mathrm{C}$, thought to be the rupture of the metal oxygen bond, is expected to be endothermic as it is with predictions ${ }^{35}$ for $\mathrm{V}, \mathrm{Cr}, \mathrm{Mn}, \mathrm{Fe}$, $\mathrm{Co}$, and $\mathrm{Ru}$ acetylacetonates and with experiments ${ }^{34}$ for $\mathrm{Fe}$ acetylacetonate decomposed in helium. But once this bond is broken, the volatile acetylacetonate species will undergo oxidation reactions that are highly exothermic, as was observed with the thermal decomposition of $\mathrm{Fe}$ acetylacetonate in oxygen ${ }^{34}$ In addition, hydrogen is a likely volatile product of thermal decomposition which will readily oxidize to $\mathrm{H}_{2} \mathrm{O}$, adding to the exothermicity.

The broad thermal decomposition centered at $335^{\circ} \mathrm{C}$ was further studied kinetically by performing TGA at various constant temperatures between 300 and $400{ }^{\circ} \mathrm{C}$. Samples of dried solutions coated onto glass spheres were placed in the TGA apparatus and heated at $50{ }^{\circ} \mathrm{C} / \mathrm{min}$ to the desired temperature and held at this operating temperature while monitoring the weight loss as a function of time. Figure 7 is an example of this time dependent weight loss for a decomposition temperature of $400{ }^{\circ} \mathrm{C}$. At all temperatures in this $100{ }^{\circ} \mathrm{C}$ range, a first-order reaction was observed. The rate constants obtained are plotted as a function of temperature in Fig. 8

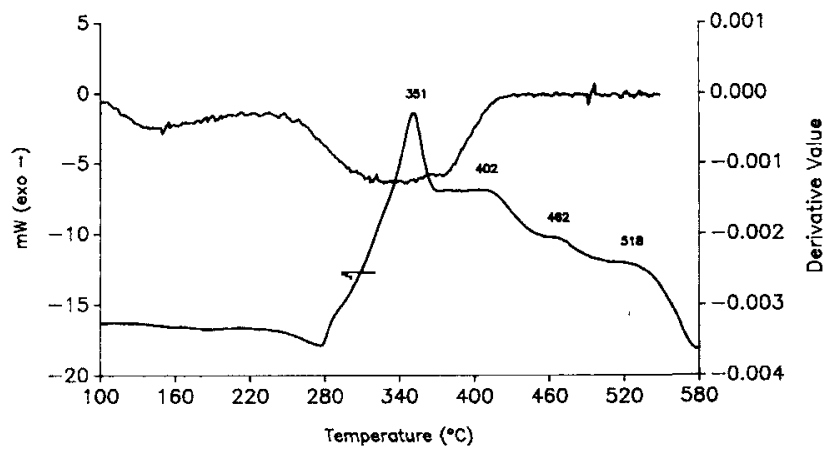

FIG. 6. Weight loss as a function of time for ramp of $50^{\circ} \mathrm{C} / \mathrm{min}$ to $400{ }^{\circ} \mathrm{C}$ and hold. The weight loss at $400{ }^{\circ} \mathrm{C}$ is first order with a rate constant of $0.217 \mathrm{~min}^{-1}$. 


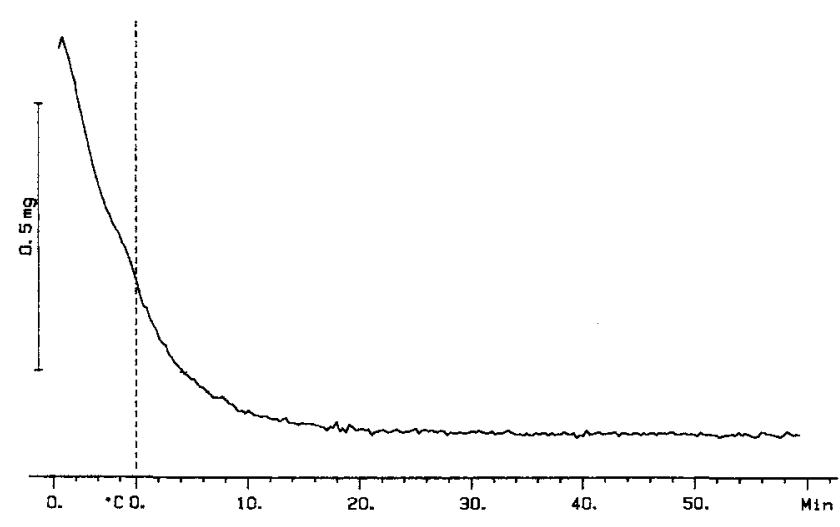

FIG. 7. DSC and DTG of $8 \%$ tin oxide ITO film.

from which an activation energy of $13.6 \mathrm{Kcal} / \mathrm{mole}$ was determined.

Based on these TGA results, pyrolysis/gas chromatography/mass spectroscopy measurements were performed for the temperatures $50,100,250,400,600$, and $1000{ }^{\circ} \mathrm{C}$ in ascending order for the $8 \%$ tin oxide sample. These results are shown in Fig. 9. Here we see the total accumulated mass as well as selected narrow mass ranges plotted as a function of time. At $50{ }^{\circ} \mathrm{C}$ a large amount of gas evolves in a large peak at 2 min retention time followed by a smaller peak at 4 min retention time. The peak at $2 \mathrm{~min}$ retention time is composed primarily of mass 98 to 102 and mass 164 to 166 . The peak at 4 min retention time is composed primarily of mass 164 to 166. This double peak is identical to that obtained for acetylacetone solvent (mass 100) under the same experimental conditions. The mass 164 to 166 is probably a product of an autocatalytic reaction of acetylacetone in the pyrolyzer. Thus, the thermal decomposition at $50{ }^{\circ} \mathrm{C}$ can be interpreted as the evaporation of solvent left in

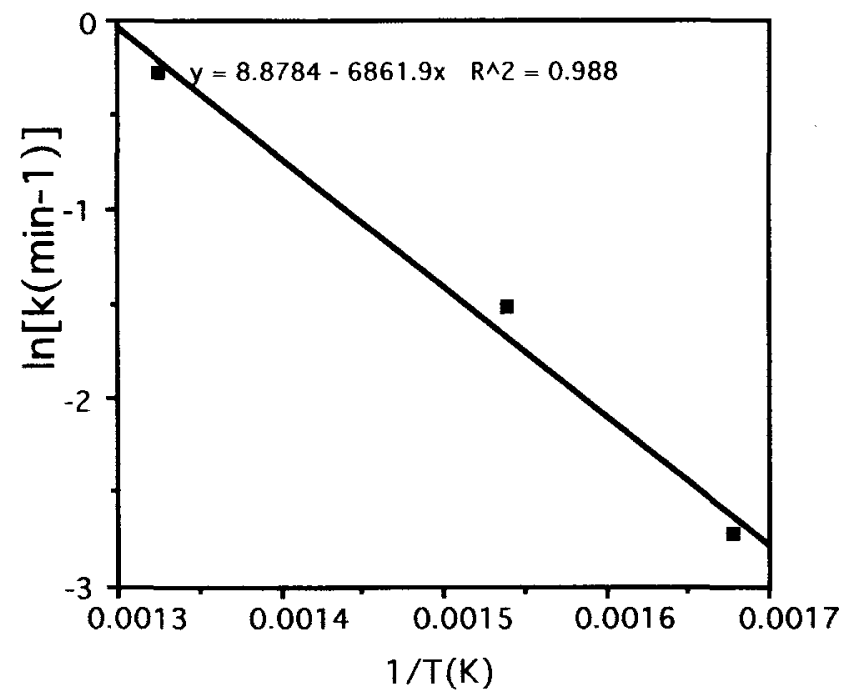

FIG. 8. Decomposition rate constant as a function of $1 / T$ for ITO films. $E_{A}=13.6 \mathrm{Kcal} / \mathrm{mole}$.

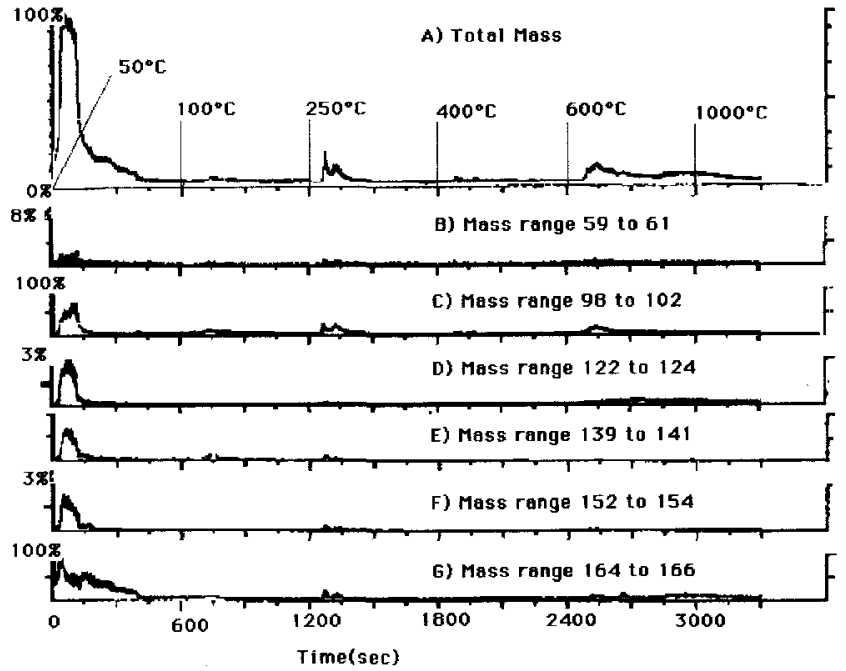

FIG. 9. Mass spectra as a function of time for the step pyrolysis to $50,100,250,400,600$, and $1000{ }^{\circ} \mathrm{C}$ : (A) total accumulated mass and $(\mathrm{B}-\mathrm{G})$ specific mass ranges.

the film after drying. At $100{ }^{\circ} \mathrm{C}$, there is very little gas evolution detected. At $250^{\circ} \mathrm{C}$, a small amount of gas evolves with a peak at 1.5 and 2.5 min retention times. These peaks are primarily mass 98 to 102 and 164 to 166 again corresponding to the mass signature of the acetylacetone solvent. At $400{ }^{\circ} \mathrm{C}$, there is very little gas evolution detected. At $600{ }^{\circ} \mathrm{C}$, a broad peak centered at 2.5 min retention time is produced, which is expanded in Fig. 10. Again this peak consists primarily of mass 98 to 102 and mass 164 to 166 . The initial part of the total accumulated mass peak is the result of the 98 to 102 mass, and the breadth of the peak is a result of the 164 to 166 mass. The reaction occurring at this temperature does not contribute very much to the weight loss as seen in Fig. 5, and for this reason we do not speculate as to what is taking place. At $1000{ }^{\circ} \mathrm{C}$, there is very little gas evolution detected. Signals for $\mathrm{HCl}$ (mass range 34 to 39 ) or nitric acid (mass range 62 to 64 ) in the mass spectra of the products of film thermal decomposition at any temperatures were not found.

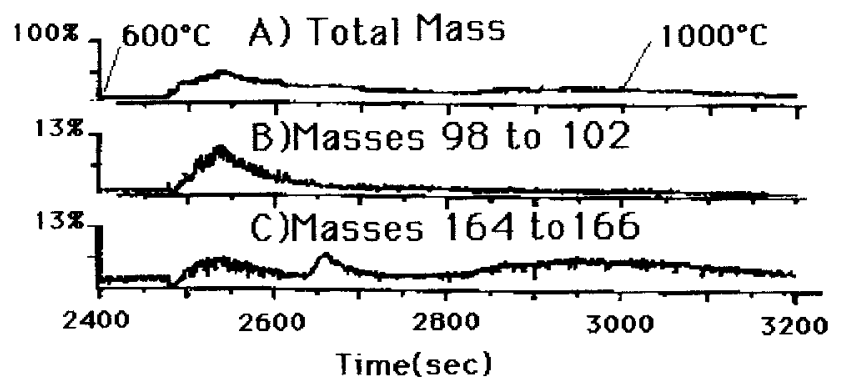

FIG. 10. Expanded mass spectra as a function of time for the step pyrolysis to 600 and $1000^{\circ} \mathrm{C}$ : (A) total accumulated mass and (B, C) specific mass ranges. 
Thus, we can deduce that the thermal decomposition of ITO films in air occurs by the following reactions:

$$
\begin{aligned}
2 \mathrm{In}\left(\mathrm{C}_{5} \mathrm{H}_{7} \mathrm{O}_{2}\right)_{3}(\mathrm{~s})+ & 3 \mathrm{O}_{2}(\mathrm{~g}) \longrightarrow \mathrm{In}_{2} \mathrm{O}_{3}(\mathrm{~s}) \\
& +6 \mathrm{C}_{5} \mathrm{H}_{6} \mathrm{O}_{2}(\mathrm{~g})+3 \mathrm{H}_{2} \mathrm{O}(\mathrm{g}) \\
\mathrm{Sn}\left(\mathrm{C}_{5} \mathrm{H}_{7} \mathrm{O}_{2}\right)_{4}(\mathrm{~s})+ & 2 \mathrm{O}_{2}(\mathrm{~g}) \longrightarrow \mathrm{SnO}_{2}(\mathrm{~s}) \\
& +4 \mathrm{C}_{5} \mathrm{H}_{6} \mathrm{O}_{2}(\mathrm{~g})+2 \mathrm{H}_{2} \mathrm{O}(\mathrm{g}),
\end{aligned}
$$

giving an amorphous oxide film. Furthermore, the volatile acetylacetonate residue may be further fragmented and/or oxidized. Smaller fragments were certainly observed in the mass spectra, but it is difficult to determine if this fragmentation was caused during thermal decomposition (at $1 \mathrm{~atm}$ ) or in the detector of the mass spectrometer (high vacuum with high voltage).

The formation of the ceramic phase in the ITO films was investigated by DSC and $\mathrm{x}$-ray analysis. Figure 6 shows a large exothermic decomposition peak for the loss of the organic molecules in the 280 to $400{ }^{\circ} \mathrm{C}$ range and an exothermic crystallization peak at approximately $518{ }^{\circ} \mathrm{C}$ with a heating rate of $40{ }^{\circ} \mathrm{C} / \mathrm{min}$. The crystallization of the film, confirmed by $\mathrm{x}$-ray analysis shown in Fig. 11, occurs at the same temperature as that of the bulk ITO powders. The $\mathrm{x}$-ray patterns show that some degree of crystallinity is present at $500{ }^{\circ} \mathrm{C}$ below the bulk crystallization temperature for the film on the borosilicate glass substrate, but it is minor in comparison to the crystallization of the remainder of the film above $518{ }^{\circ} \mathrm{C}$. There is also a transition in the $450-470{ }^{\circ} \mathrm{C}$ range, which is the glass transition of the amorphous film. When repeated thermal cycles are applied to this film across the glass transition temperature, this transition is seen to reduce and then disappear. After $120 \mathrm{~min}$ above $518{ }^{\circ} \mathrm{C}$, the glass transition was virtually nonexistent, indicating a uniform crystalline structure had been formed. Films that were heated in air at $500{ }^{\circ} \mathrm{C}$ for $1 \mathrm{~h}$ were transparent, but

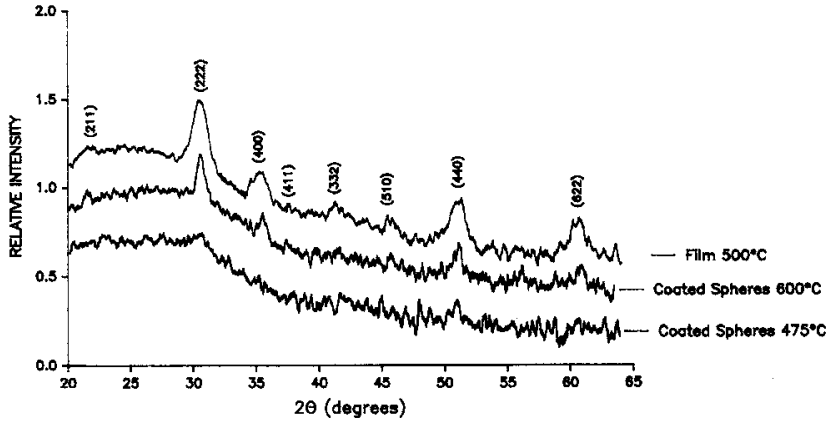

FIG. 11. X-ray diffraction of $8 \%$ tin oxide ITO film.

were not electrically conductive. Increasing the time held at $500{ }^{\circ} \mathrm{C}$ in reducing gas (until metallization) improved the electrical conductivity, but not as much as thermal treatments in air above $462{ }^{\circ} \mathrm{C}$, suggesting that improved microstructure and/or crystallinity is needed to enhance electrical conductivity.

As a result of these thermal decomposition experiments, the following heat treatment schedule was developed for ITO films dip coated on borosilicate glass substrates: (i) drying in air at $25^{\circ} \mathrm{C}$ for $1 \mathrm{~h}$, then at $100{ }^{\circ} \mathrm{C}$ in a vacuum oven overnight, (ii) thermal decomposition in dry air at $500{ }^{\circ} \mathrm{C}$ for $1 \mathrm{~h}$ (giving a crystalline film), and (iii) reduction at $500{ }^{\circ} \mathrm{C}$ for various periods of time in forming gas.

The surface chemistry of the $8 \% \mathrm{SnO}_{2}$ film after thermal treatment, including reduction, was measured by $\mathrm{ESCA}^{21}$ (not shown). It showed In, Sn, and $\mathrm{O}$ as major peaks [i.e., $N(E) / E>60 \times 10^{3}$ counts/s] and $\mathrm{C}, \mathrm{N}$, and $\mathrm{Al}$ as minor peaks [i.e., $N(E) / E<1.5 \times$ $10^{3}$ counts $\left./ \mathrm{s}\right]$. The presence of nitrogen is probably due to its adsorption from air. The carbon is most likely residual from the thermal decomposition of the metal-

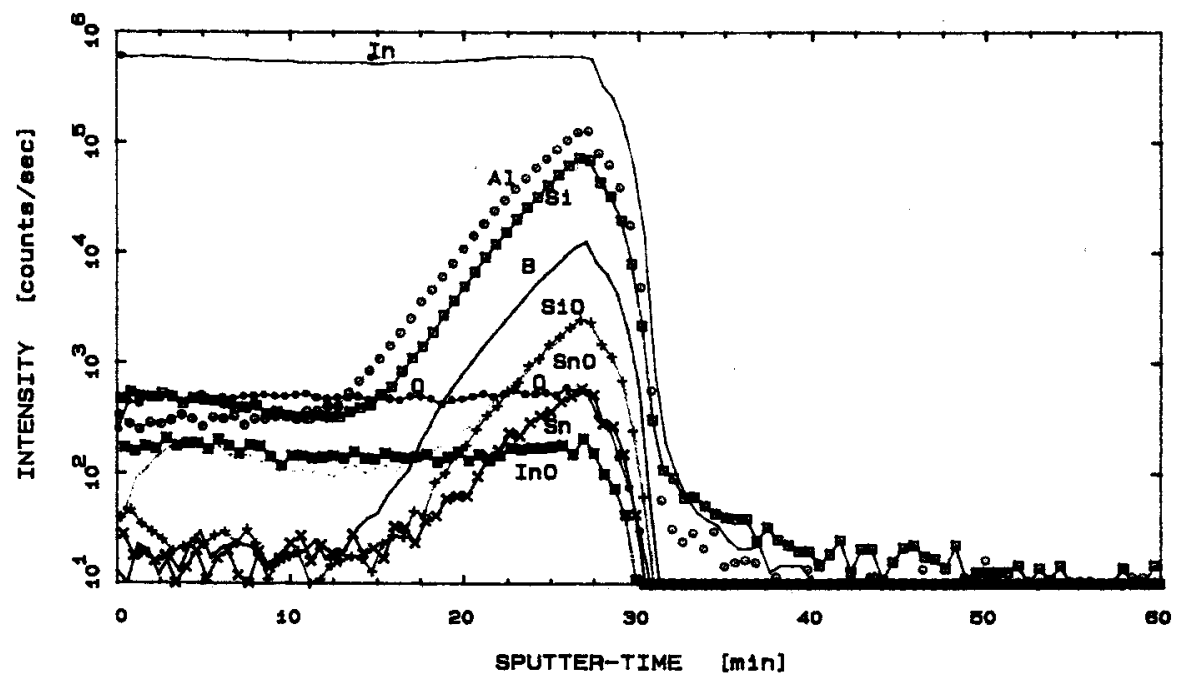

FIG. 12. SIMS profile of $8 \%$ tin oxide ITO film. 
organic deposit, and the aluminum is probably due to substrate diffusion through the film.

An argon ion sputtered SIMS ${ }^{22}$ profile of the $8 \%$ $\mathrm{SnO}_{2}$ film after all thermal treatments, including reduction, is shown in Fig. 12. Here we see that the interface between the film and the substrate is easily observed. The sputtering rate was not calibrated for this sample. But for a sample of $\mathrm{Ta}_{2} \mathrm{O}_{5} / \mathrm{Ta}^{36}$ under identical sputtering conditions, the sputtering rate was found to be $12 \AA / \mathrm{min}$, allowing a crude calculation of the film thickness as $\approx 500 \AA$. The SIMS profile shows that the In and $\mathrm{O}$ remain relatively constant over the thickness of the film. In addition $\mathrm{SnO}$ is deficient at the surface of the film and appears to diffuse to the film/substrate interface where it is concentrated. Several elements diffuse from the substrate into the film. These include $\mathrm{Al}, \mathrm{Si}$, and B. Indium may also diffuse into the substrate since it was not found by $x$-ray fluorescence of the substrate, yet is observed in the SIMS profile of the substrate below the surface of the film. The reason that the $\mathrm{Si}, \mathrm{Al}$, and $\mathrm{B}$ signals drop off at the same depth as the In and Sn signal is that the ITO film and the glass substrate are different matrices. The ITO film is more easily sputtered than the borosilicate glass substrate giving a larger signal.

The surface structure of the $8 \% \mathrm{SnO}_{2}$ film is shown in Fig. 13 using atomic force microscopy $\left(\mathrm{AFM}^{10}\right)$. Here we see there is a uniform surface structure for a 9.9 by $10 \mu \mathrm{m}$ cross section [see Fig. 13(a)]. At further magnification [see Fig. 13(b) and 13(c)] we can see undulations to the surface which are probably grains of the ITO crystal structure since their RMS roughness is $44 \AA$ compared to a value of $6.7 \AA$ for the substrate alone. At the highest magnification [Fig. 13(c)], we can see that the crystallites are approximately $50 \AA$ in diameter.

\section{Optical and electrical property measurement}

Samples prepared with various tin dopant levels and thermal reduction treatments gave conductivity curves which are similar to those seen by others. ${ }^{1,37}$ Figure 14 shows a decrease in film resistivity as the reduction time increases. For each reduction time, the resistivity shows a minimum near $8-10 \%$ weight $\mathrm{SnO}_{2}$ (the optimal dopant level). The best measured resistivity value in these experiments was $1.01 \times 10^{-3} \Omega \cdot \mathrm{cm}$ for a film with $8 \%$ weight $\mathrm{SnO}_{2}$ reduced in forming gas for $720 \mathrm{~min}$. Longer reduction times to the point of converting the oxide film to a metal film (not shown in this figure) did not produce lower resistivity values than those shown for 720 min reduction time in forming gas. The formation of a metal film is easily observed by its change from transparent to a grey-brown color.

The optical transmittance curve for the film with $8 \%$ weight $\mathrm{SnO}_{2}$, reduced for $720 \mathrm{~min}$, was measured

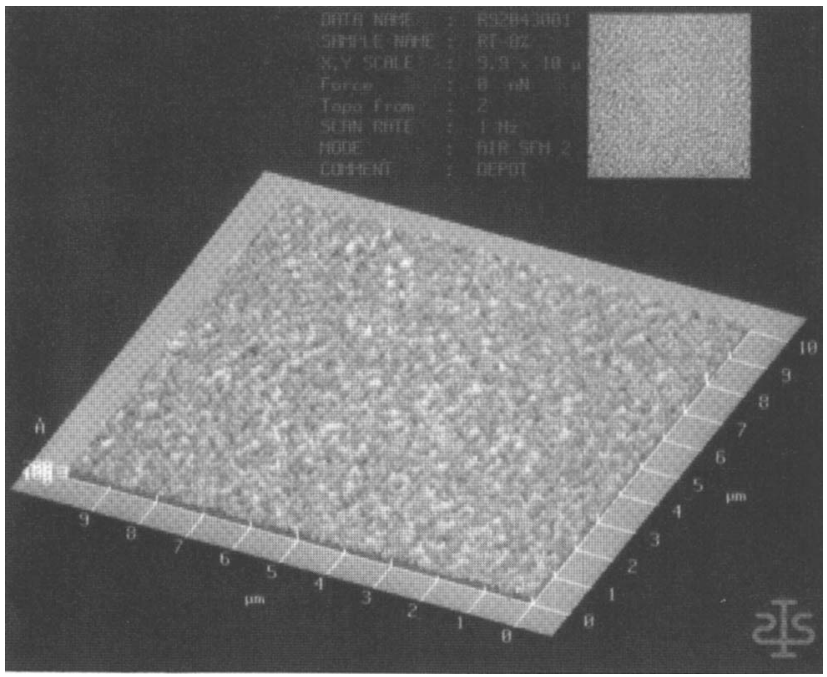

(a)

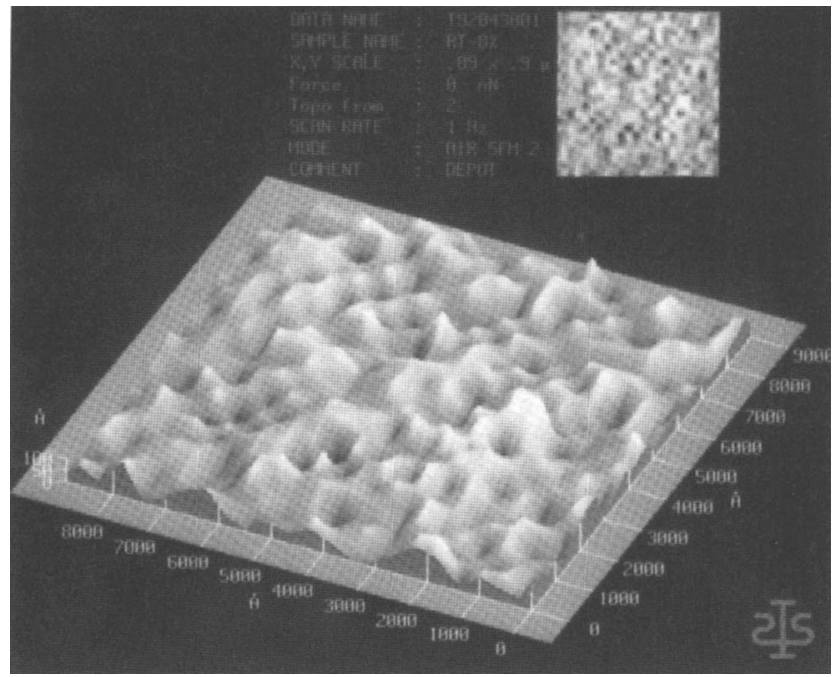

(b)

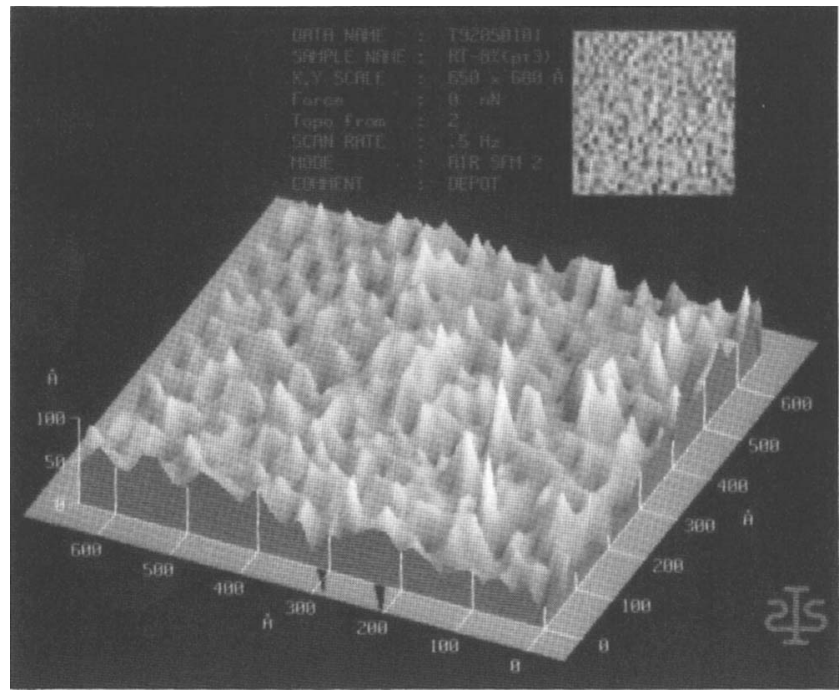

(c)

FIG. 13. AFM of $8 \%$ tin oxide ITO film at three magnifications: (a) $9.9 \times 10 \mu \mathrm{m}$, (b) $0.89 \times 0.9 \mu \mathrm{m}$, and (c) $650 \times 680 \AA$. 


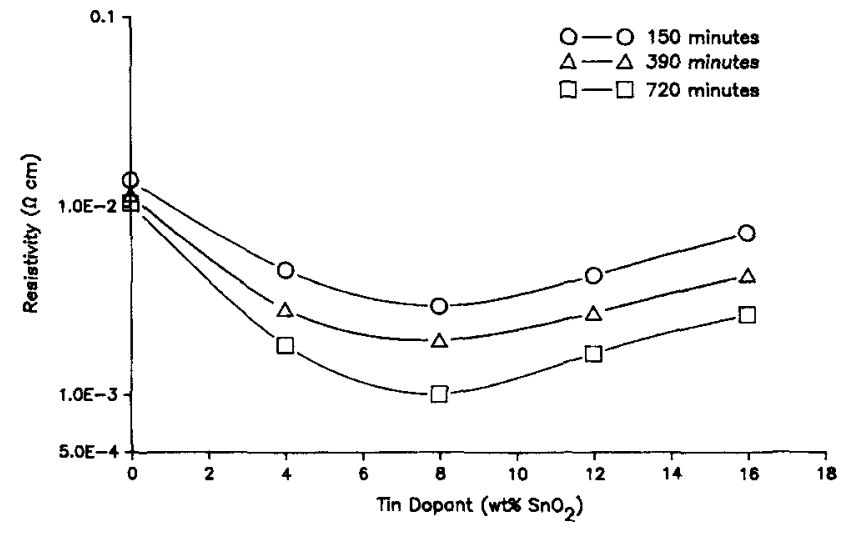

FIG. 14. Resistivity as a function of time dopant concentration and reduction time at $500{ }^{\circ} \mathrm{C}$ in reducing gas.

over a wavelength range of 300 to $900 \mathrm{~nm}$, as shown in Fig. 15. The sample had a transmittance of $89.7 \%$ at $400 \mathrm{~nm}$ for a sample coated on two sides, which corresponds to a calculated transmittance of $94.9 \%$ for a single film $273 \mathrm{~nm}$ thick. The minimum resistivity at $8 \mathrm{wt} . \%$ tin oxide occurs at a greater tin doping level than that in sputtered films, which may indicate either a greater solubility of tin in the indium oxide structure, or a difference in the excess tin phases.

\section{CONCLUSIONS}

Thermal decomposition of an indium and tin acetylacteonate deposit dip coated onto a borosilicate glass substrate from an acetylacetone solution produced good $\mathrm{In}_{2} \mathrm{O}_{3}-\mathrm{SnO}_{2}$ films. Film thicknesses of $273 \mathrm{~nm}$, containing $8 \mathrm{wt}$.\% tin oxide, thermally decomposed at $500{ }^{\circ} \mathrm{C}$ and reduced for $720 \mathrm{~min}$ in forming gas at $500{ }^{\circ} \mathrm{C}$ gave resistivities of $\sim 1.01 \times 10^{-3} \Omega \cdot \mathrm{cm}$ with an optical transparency of $\sim 95 \%$ at $400 \mathrm{~nm}$. This optical transparency is similar to that obtained by sputtering. The electrical resistivities of these films are a factor of two less than the best produced by sputtering. Controlled microstructure, electrical and optical properties of the

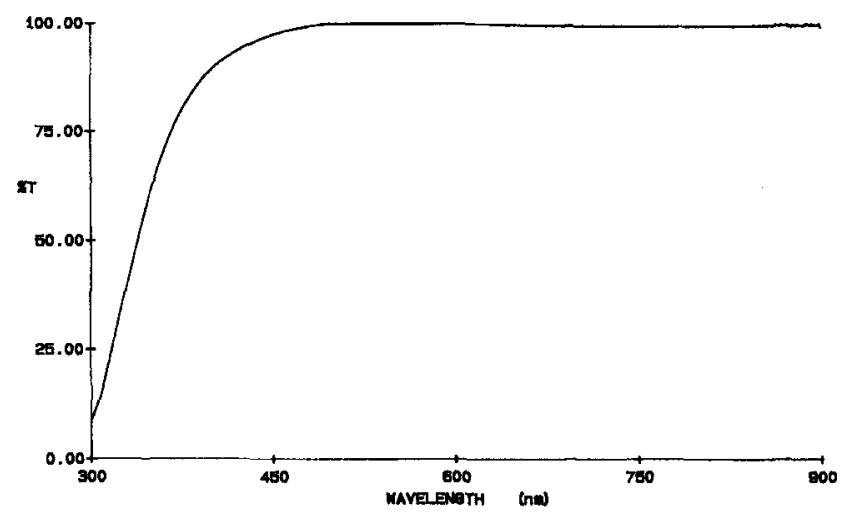

FIG. 15. Optical transmittance of $8 \%$ ITO film.
ITO films result from an understanding of the film thermal decomposition, crystallization, and reduction steps which must be further optimized to give electrical resistivities as good as sputtered films.

\section{ACKNOWLEDGMENTS}

This research was sponsored by the Swiss National Science Program NFP No. 19. The authors would like to thank Jean Daniel Neuvecelle for the AFM photographs, Brian Senior for the SEM photographs used, and Anahita Jamshidi for her work in preparing the samples for the resistivity measurements.

\section{REFERENCES}

1. T. Maruyama and A. Kojima, Jpn. J. Appl. Phys. 27 (10), L1829-1831 (1988).

2. A. L. Dawar and J.C. Joshi, J. Mater. Sci. 19, 1-23 (1984).

3. N. J. Arfsten, R. Kaufman, and H. Dislich, in Ultrastructure Processing of Advanced Ceramics, edited by J.D. Mackenzie and D. R. Ulrich (John Wiley, New York, 1984), pp. 189-196.

4. N.J. Arfsten, R. Kaufman, and H. Dislich, German Patent DE 3300589 , July 12, 1984.

5. I. Hamberg and C.G. Granqvist, J. Appl. Phys. 60 (11), R123-R159 (1986).

6. G. Frank, H. Köstlin, and A. Rabenau, Phys. Status Solidi (A) 52, 231-238 (1979).

7. J. C.C. Fan and J. B. Goodenough, J. Appl. Phys. 48 (8), 3524-3531 (1977).

8. Desag, Grünenplan, Germany (AF-45).

9. Omicron Spectrometer, Kevex Instruments, San Carlos, CA 94070.

10. SFM-BD2-210, Park Scientific Instruments, Mountain View, CA 94043.

11. Fluka, Buchs, Switzerland (technical grade).

12. Fluka, Buchs, Switzerland (reagent grade).

13. Nicolet $\mathbf{5 1 0}$ FTIR spectrometer, Nicolet Analytical, Madison, WI.

14. Carbagas, Lausanne, Switzerland (technical grade).

15. Mettler TG 50, Mettler, Zurich, Switzerland.

16. Mettler DSC 30, Mettler, Zurich, Switzerland.

17. Chemical Data System Pyroprobe 200, CDS, Oxford, PA.

18. Varian 3400, Varian Ass., Sunnyvale, CA.

19. Finnigan-MAT Ion Trap Mass Spectrometer ITMS, FinniganMAT, San Jose, CA.

20. F. P. Scanlan and R. Houriet, J. Trace Microprobe Technol. 9, 177-199 (1991).

21. PHI 5500 Perkin-Elmer, Norwalk, CT 00856.

22. A-DIDA 3000(Atomika) Perkin-Elmer, Norwalk, CT 00856.

23. L. J. van der Pauw, Philips Res. Rep. 13 (1), 1-9 (1958).

24. S. M. Sze, Physics of Semiconductor Devices, 2nd Edition (John Wiley \& Sons, New York, 1981), pp. 31-33.

25. Perkin-Elmer Lambda 6, Norwalk, CT 00856.

26. J.D. Roberts and M.C. Caserio, Basic Principles of Organic Chemistry (W. A. Benjamin, Inc., New York, 1965), p. 498.

27. This peak at $346 \mathrm{~nm}$ is similar to that observed for $\mathrm{Al}\left(\mathrm{C}_{5} \mathrm{H}_{7} \mathrm{O}_{2}\right)_{2}$.

28. A. L. Allred and D. W. Thompson, Inorg. Chem. 7, 1196-1201 (1968).

29. R. W. Jones and R. C. Fay, Inorg. Chem. 12, 2599-2606 (1973). 30. J. W. Faller and A. Davidson, Inorg. Chem. 6, 182-184 (1967).

31. D. W. Thompson, J. F. Lefelhoxz, and K. S. Wong, Inorg. Chem. 11, 1139-1141 (1972). 
32. N. Inagaki and J. Ohkubo, J. Appl. Polym. Sci. 43 (4), 793-800 (1991).

33. B. V. Deryagin, DAN USSR. 39, 11 (1943); reviewed in B. M. Deryagin and S. M. Levi, The Focal Press, London (1964).

34. N.B. Morozova, V.N. Mit'kin, and I. K. Igumenov, Russ. J. Inorg. Chem. 33 (10), 1459-1464 (1988).
35. P. Sharpe and D.E. Richardson, J. Am. Chem. Soc. 113, $8339-8340$ (1991).

36. $\mathrm{Ta}_{2} \mathrm{O}_{5} / \mathrm{Ta}$ certified reference material, CRM $261 \mathrm{R}, \mathrm{BCR}$ Brussels.

37. J. L. Vossen, RCA Rev. 32, 289-296 (1971). 